\title{
Vertical integration, market foreclosure and quality investment
}

\author{
Roberto Hernán González • Praveen Kujal
}

\begin{abstract}
We study incentives to vertically integrate in an industry with vertically differentiated downstream firms. Vertical integration by one of the firms increases production costs for the rival. Increased production costs negatively affects quality investment both by the integrated firm and the unintegrated rival. Quality investment by both firms decreases under any (vertical integration) scenario. The decrease in quality invesment by both firms softens competition among downstream firms. By integrating first, a firm always produces the high quality good and earns higher profits. A fully integrated industry, with increased product differentiation, is observed in equilibrium. Due to increase in firm profits, social welfare under this structure is greater than under no integration.
\end{abstract}

Keywords Vertical integration - Quality investment - Market power • Product differentiation

JEL Classification $\mathrm{L} 15 \cdot \mathrm{L} 22 \cdot \mathrm{L} 42$

R. Hernán González ( $\bowtie)$

Economic Science Institute, Chapman University,

One University Drive, Orange, CA 92866, USA

e-mail: roberto.hernangonzalez@gmail.com

P. Kujal

Departamento de Economía, Universidad Carlos III de Madrid,

Calle Madrid 126, 28903 Getafe, Spain

e-mail:kujal@eco.uc3m.es 


\section{Introduction}

Commenting on vertical mergers, a recent OECD report ${ }^{1}$ highlights that an undesirable effect of a vertical merger can be an increase in market power due to lowered quality investment by firms. Vertical mergers may also work towards facilitating coordination among post-merger firms, making tacit agreement on the coordinated outcome easier. The effect of decreased investment in quality limits "the possibility of selection of products by the end consumer". Therefore, products of other producers may become less attractive as substitutes than they were prior to the vertical merger (ibid, p. 21).

In this paper, we address how vertical integration impacts quality investment. We show that while the direct effect of vertical integration and foreclosure is an increase in production costs, it also affects investment in quality for both the integrated and the unintegrated firm. Quality investment for both firms decreases. However, the unintegrated firm decreases its quality investment by a greater amount. The final effect of this is an increase in product differentiation resulting in softening of competition. ${ }^{2}$

We develop a simple model that looks at the relationship between vertical integration and market foreclosure in vertically differentiated industries. Using the same industry structure as in Ordover et al. (1990, OSS henceforth) we show that partial, or full, sequential integration results in a decrease in quality investment by both the low and high quality firm. Interestingly, a vertically integrating firm affects both production and quality costs for its unintegrated rival. Considering only sequential vertical mergers, the equilibrium market structure obtained is full integration, where total welfare is greater than under no, or partial, integration.

Integration between an upstream and a downstream firm is a strategic decision that affects rival profits and market structure. The decision of the integrated firm to not sell the input to its rival has two effects in our model. First, it decreases competition in the upstream market, resulting in increased production costs for the downstream rival. ${ }^{3}$ The second important effect is upon quality investment. The unintegrated firms' quality investment decision is conditioned by the higher production costs that it faces. This negatively affects its quality investment. In order to best respond to this, the high quality firm also invests less in quality. The decrease in quality investment, however, is greater for the unintegrated low quality firm. This results in diminished market competition due to the increase in the degree of product differentiation. Further, there is no equilibrium in pure strategies where the firm that integrates first produces the low quality good.

\footnotetext{
${ }^{1}$ OECD 2007, Policy Roundtable on Vertical Mergers, http://www.oecd.org/dataoecd/25/49/ 39891031.pdf.

${ }^{2}$ This results does not hold when firms merge simultaneously in the first stage. The strategic motive of raising rivals' costs, which is the focus of most papers, is lost in simultaneous vertical mergers.

${ }^{3}$ The effect of reducing competition in the output stage by increasing input costs has been studied by Salop and Scheffman $(1983,1987)$.
} 
Our paper differs from OSS in an important aspect. OSS assume that the integrated firm can commit to either not selling the input to the unintegrated downstream firm, or to selling the input at a specific price. ${ }^{4}$ They obtain the initial equilibrium without the commitment assumption, ${ }^{5}$ with the downstream firms transferring some rents (as integration bids) to the upstream rivals. We, however, do not need to use this commitment mechanism. Counter-integration does not restore the initial situation in our paper. This is due to the fact that the integration process affects the decisions on long run variables, such as quality investment, thus altering the final equilibrium.

As a strategic decision affecting competition, ${ }^{6}$ the literature on vertical integration has focused on mergers between input and output producers. The analysis has focused on conditions under which vertical integration and foreclosure takes place, and when they can increase welfare. It is noteworthy that little has been said on the effect of investment in long run variables such as quality, or R\&D.

Some recent papers have looked at $R \& D$ in vertically related industries. Stefanadis (1997) studies the effect of R\&D investment in a successive duopoly. ${ }^{7}$ Firms integrate strategically to reduce the incentives of the unintegrated upstream firm to invest in R\&D. Banerjee and Lin (2003) study the effect of downstream innovation in vertically related markets. By increasing demand for the input, downstream R\&D increases the price for the downstream firm. This lowers the benefit of R\&D in the downstream firm, plus it raises rivals' costs. Due to this, the downstream oligopolist invests more in R\&D than a monopoly does. Brocas (2003), meanwhile, studies innovation in the upstream market. Adopting a new technology has a switching cost and prices of licenses, for technology, vary with this cost. Easily substitutable technologies command a low price and innovators benefit from a lock in effect for technologies with high switching costs. More importantly, the price affects the ex-ante private incentives to invest in $\mathrm{R} \& \mathrm{D}$ resulting in the disappearance of efficient technologies with low (switching) costs. In such a framework, innovators and producers may find it profitable to integrate vertically before investing.

The effect on quality investment of vertical integration has also been studied in regulated industries. ${ }^{8}$ Vickers (1995) points out that an integrated monopolist can raise the cost of its rivals by lowering the quality of the input provided to the unintegrated downstream firms. Meanwhile, others have studied how quality investments can be used by integrated firms to foreclose their rivals when an upstream monopolist also participates in the downstream market (see Economides 1998; Sibley and Weisman 1998; Foros 2004).

\footnotetext{
${ }^{4}$ Without competing with the remaining upstream firm.

${ }^{5}$ This assumption has been criticized in the literature (see Reiffen 1992 and Avenel and Barlet 2000).

${ }^{6}$ See Ordover et al. (1990) and Hart and Tirole (1990).

${ }^{7}$ In his model, there are several firms that supply the input. However, only two of them invest in R\&D to obtain new technology.

${ }^{8} \mathrm{We}$ would like to thank one of the referees for pointing this out.
} 
The paper is organized as follows: in the following section, we describe the basic model; following this we study several different market structures; then we analyze the industry structure in equilibrium, followed by an analysis of the welfare effects of integration; finally, we conclude.

\section{The model}

Consider a successive duopoly where two upstream firms, $U_{1}$ and $U_{2}$, produce a homogenous good at constant marginal costs. The input is transformed oneto-one by the downstream firm into a final good. The final product is vertically differentiated. ${ }^{9}$ The quality of the good is decided by each downstream firm. Let us denote $s_{i}$ as the quality of the good produced by downstream firm $D_{i}$, $i=1,2 \cdot{ }^{10}$ Production costs of the final good are given by

$$
C_{D_{i}}\left(s_{i}, q_{i}\right)=c_{i} \cdot q_{i}+\frac{1}{2} s_{i}^{2}, i=1,2
$$

where $c_{i}$ is the input price and $q_{i}$ is firm production.

Production costs are independent of quality costs. Note that quality costs are endogenous and are sunk in the output competition stage. Then, downstream firms' profit functions are

$$
\pi_{D_{i}}=\left(p_{i}-c_{i}\right) q_{i}-\frac{s_{i}^{2}}{2}, i=1,2
$$

Without loss of generality, we assume upstream marginal costs are zero. Upstream firms' profit functions can then be written as $\pi_{U_{i}}=m_{i} X_{i}$, where $m_{i}$ is the input price charged by firm $i$ and $X_{i}$ is its demand.

Assume that a continuum of consumers exist on the demand side. ${ }^{11}$ Each consumer has parameter $\theta$, where $\theta$ is distributed uniformly in the interval $[0, \bar{\theta}]$. Consumers have unit demand and utility

$$
U= \begin{cases}\theta s-p & \text { purchasing one unit of the good with quality } s \text { and price } p \\ 0 & \text { otherwise }\end{cases}
$$

Denote by $\hat{\theta}_{H L}\left(=\frac{p_{H}-p_{L}}{s_{H}-s_{L}}\right)$, the consumer that is indifferent between buying the high and the low quality good, and by $\hat{\theta}_{0 L}\left(=\frac{p_{L}}{s_{L}}\right)$, the consumer that is indifferent between buying the low quality good and not buying at all. Given

\footnotetext{
${ }^{9}$ The quality investment structure in our model is the same as in Motta (1993).

${ }^{10}$ See Shaked and Sutton (1983).

${ }^{11}$ We use the standard product differentiation developed in Shaked and Sutton (1983). Also see Motta (1993).
} 


\section{Integration $\longrightarrow \begin{aligned} & \text { 2. Quality } \\ & \text { Investment }\end{aligned} \rightarrow \begin{aligned} & \text { 3. Input } \\ & \text { Competition }\end{aligned} \rightarrow \begin{aligned} & \text { 4. Counter- } \\ & \text { Integration }\end{aligned} \rightarrow \begin{aligned} & \text { 5. Output } \\ & \text { Competition }\end{aligned}$}

Fig. 1 Timing of the game

this, the indirect demand functions are obtained for the high and low quality good

$$
\begin{aligned}
p_{H} & =s_{H}\left(\bar{\theta}-q_{H}\right)-s_{L} q_{L} \\
p_{L} & =s_{L}\left(\bar{\theta}-q_{H}-q_{L}\right)
\end{aligned}
$$

where $q_{H}$ and $q_{L}$ are the quantities produced by the high and low quality downstream firms, respectively.

We consider a five stage game (see Fig. 1). In the first stage (and maintaining the OSS notation), downstream firms, $D_{1}$ and $D_{2}$, negotiate with the upstream firms, $U_{1}$ and $U_{2}$, to integrate or not. Simplifying the process, and in order to maintain comparability with OSS, we assume that firms $D_{i}$ make a take it or leave it offer, $b_{i}$, to firms $U_{i}, i=1,2 .{ }^{12}$ Firm $D$ and $U$ merge to form a single firm $F .{ }^{13}$

In the second stage, firms $D_{1}$ and $D_{2}$, or the integrated firm(s), select profit maximizing levels of quality. In the third stage, the upstream firms, integrated or not, select the price at which they sell the input. We assume Bertrand competition in the input market. ${ }^{14}$ If both upstream firms compete then the price in equilibrium equals marginal cost. Similarly, the price would be the same if an integrated and unintegrated firm compete in the input market. This eliminates the strategic incentives to integrate (and increases rival costs). We assume that the integrated firm does not sell the input to its rival, focusing instead on the case of market foreclosure on the part of the integrated firm. Market foreclosure leaves its rival acting as a monopolist against the unintegrated downstream firm. In this sense, we consider the integration process as an exclusive contract, ${ }^{15}$ where both integrated firms commit to not

\footnotetext{
${ }^{12}$ One can formulate the bidding at this stage in several ways. One can use the structure in OSS, which we use. OSS then study the robustness of their results with two different formulations. In one, upstream firms bid, and in the other, downstream firms bid for the two upstream firms. Their main results do not change. Only bids and distribution of profits are different in the first case.

${ }^{13}$ Given the symmetry of the upstream firms, we denote the integrated firm, between $D_{i}$ and $U_{i}$, as $F_{i}$.

${ }^{14}$ The advantage of price competition is that it isolates the problem of the strategic value of vertical integration for the integrating firm. For a detailed discussion see OSS.

${ }^{15}$ The incentives to foreclose potential entrants using exclusive contracts has been studied by Aghion and Bolton (1987) and Rasmusen et al. (1991). More recently, Chen and Riordan (2007) analyze the incentives of an integrated firm to foreclose an un-integrated (equally, or more efficient) upstream rival signing an exclusive contract.
} 
selling their product to the other unintegrated firms. We exogenously impose this commitment ${ }^{16}$ in order to focus on the effects of foreclosure. ${ }^{17}$ Without this commitment, and to ensure foreclosure, we would need to introduce more structure into the game. ${ }^{18}$

Notice that the unintegrated firm can integrate in the fourth stage. The integration process is the same as in the first stage. Unintegrated firm $D$ makes a take it or leave it offer to the (unintegrated) $U$ firm. If the latter accepts, then they integrate forming firm $F$. A firm integrating first decides on its strategy, taking into account that its rivals are not integrated. This clearly affects the quality investment decision, and those made in the output and the input markets. Unintegrated firms can counter-integrate later, thus restoring the initial situation. However, as counter-integration occurs after quality investment, competition in qualities results in different qualities. As a consequence, output and prices are different from when no integration occurs. Finally, in stage five, the firms compete in quantities.

This timing structure (same as in OSS) allows us to study the incentives of integrated firms to foreclose their rivals and the possible counter-strategies that an unintegrated rival could take. We can also study the effect of long term variables. This is important, as even if firms counter-integrate later, integrated firms can affect their rivals by changing their quality investments. In this sense, we allow integrated firms to set their long run decisions before the other firm can counter-integrate. ${ }^{19}$

We can have five possible market structures depending upon how firms vertically integrate. They are: No Integration (NI), two cases of Partial Integration $\left(P I_{H}\right.$, where one of the firms integrates in the first stage of the game and produces high quality, and $P I_{L}$, where it produces low quality) and two cases of Full sequential Integration $\left(F I_{H}\right.$ and $\left.F I_{L}\right)$. In $F I_{H}\left(F I_{L}\right)$ one of the firms integrates in the first stage and produces the high (low) quality, while the other integrates in the fourth stage and produces the low (high) quality. ${ }^{20}$

\footnotetext{
${ }^{16}$ As in Salinger (1988) and OSS. OSS's commitment is more complex. They assume that the integrated firm can decide either to not sell the product to its rival, or to supply it if the remaining unintegrated downstream firm is setting a high price. This assumption has been criticized by Reiffen (1992).

${ }^{17}$ The evidence of foreclosure in empirical studies is inconclusive (see Lafontaine and Slade 2007 and Cooper et al. 2005, for an extensive review of this literature). Martin et al. (2001) find evidence of foreclosure in an experimental market. In their design, the vertically integrated firm forecloses its downstream rival in $73 \%$ of the cases, with the unintegrated firm profits being only $4 \%$ of the industry profits.

${ }^{18}$ For example, Chen (2001) substitutes the need for commitment with switching costs of one input for another. While, Avenel and Barlet (2000) and Choi and Yi (2000) allow the integrated firm to choose a specific technology, resulting in their inputs not being perfect substitutes.

${ }^{19} \mathrm{This}$ is along the lines of the argument made by the OECD. Vertical integration can produce an increase in market power due to lowered quality investment.

${ }^{20} \mathrm{We}$ maintain the notation followed by OSS.
} 
In the following section we obtain the quality, output and prices for each one of the market structures mentioned above. The game is solved using subgame perfection and we study equilibria in pure strategies only. Finally, we discuss the market structure that emerges in equilibrium.

\section{No Integration (NI)}

Assuming that no firm integrates, we first solve for outputs in the final stage. Firm $D_{i}$ maximizes profits, $\max _{q_{i}} \pi_{D_{i}}=\left(p_{i}-c_{i}\right) q_{i}-\frac{s_{i}^{2}}{2}$. Let's assume that firm $D_{1}$ produces high quality. ${ }^{21}$ The first order conditions

$$
\begin{aligned}
& \frac{\partial \pi_{D_{1}}}{\partial q_{1}}=-2 q_{1} s_{1}+s_{1} \bar{\theta}-c_{1}-q_{2} s_{2}=0 \\
& \frac{\partial \pi_{D_{2}}}{\partial q_{2}}=-2 q_{2} s_{2}+s_{2} \bar{\theta}-c_{2}-q_{1} s_{2}=0
\end{aligned}
$$

give us the reaction functions

$$
\begin{aligned}
& q_{1}=\frac{s_{1} \bar{\theta}-c_{1}-q_{2} s_{2}}{2 s_{1}} \\
& q_{2}=\frac{s_{2} \bar{\theta}-c_{2}-q_{1} s_{2}}{2 s_{2}}
\end{aligned}
$$

Solving for the equilibrium quantities, $q_{1}\left(s_{1}, s_{2}, c_{1}, c_{2}\right), q_{2}\left(s_{1}, s_{2}, c_{1}, c_{2}\right)$, we obtain

$$
\begin{aligned}
& q_{1}\left(s_{1}, s_{2}, c_{1}, c_{2}\right)=\frac{\left(2 s_{1}-s_{2}\right) \bar{\theta}-2 c_{1}+c_{2}}{4 s_{1}-s_{2}} \\
& q_{2}\left(s_{1}, s_{2}, c_{1}, c_{2}\right)=\frac{s_{1} s_{2} \bar{\theta}-2 c_{2} s_{1}+c_{1} s_{2}}{s_{1}\left(4 s_{1}-s_{2}\right)}
\end{aligned}
$$

and corresponding profits for these quantities are

$$
\begin{aligned}
& \pi_{D_{1}}\left(s_{1}, s_{2}, c_{1}, c_{2}\right)=\frac{s_{1}\left(\left(2 s_{1}-s_{2}\right) \bar{\theta}-2 c_{1}+c_{2}\right)^{2}}{\left(4 s_{1}-s_{2}\right)^{2}}-\frac{s_{1}^{2}}{2} \\
& \pi_{D_{2}}\left(s_{1}, s_{2}, c_{1}, c_{2}\right)=\frac{\left(s_{1} s_{2} \bar{\theta}-2 c_{2} s_{1}+c_{1} s_{2}\right)^{2}}{s_{2}\left(4 s_{1}-s_{2}\right)^{2}}-\frac{s_{2}^{2}}{2}
\end{aligned}
$$

\footnotetext{
${ }^{21}$ There is a symmetrical equilibrium with firm $D_{1}\left(D_{2}\right)$ producing low (high) quality.
} 
Fig. 2 Quality reaction functions under No Integration $\left(R_{i}^{N I}\right.$ for firm $i=1,2)$. NI is the Nash Equilibrium

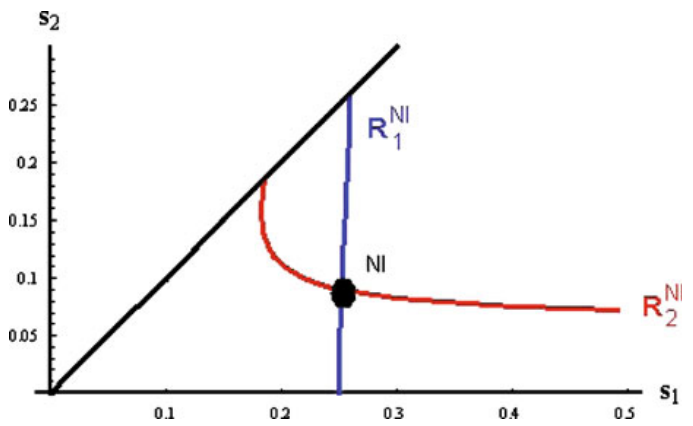

In the third stage of the game, firms $U_{1}$ and $U_{2}$ compete in prices for the input demand $\left(q_{1}+q_{2}\right)$. Price competition in a homogenous input gives us price equal to marginal cost in equilibrium, i.e., $c_{i}=0, i=1,2$.

In the second stage, downstream firms choose quality levels, maximizing profits

$$
\begin{aligned}
& \pi_{D_{1}}\left(s_{1}, s_{2}, 0,0\right)=\frac{s_{1}\left(2 s_{1}-s_{2}\right)^{2} \bar{\theta}^{2}}{\left(4 s_{1}-s_{2}\right)^{2}}-\frac{s_{1}^{2}}{2} \\
& \pi_{D_{2}}\left(s_{1}, s_{2}, 0,0\right)=\frac{s_{1}^{2} s_{2} \bar{\theta}^{2}}{\left(4 s_{1}-s_{2}\right)^{2}}-\frac{s_{2}^{2}}{2}
\end{aligned}
$$

The implicit reaction functions obtained from the first order condition, $\frac{\partial \pi_{1}}{\partial s_{1}}=0$ and $\frac{\partial \pi_{2}}{\partial s_{2}}=0$, are

$$
\begin{aligned}
& s_{1}=\frac{\left(16 s_{1}^{3}-12 s_{1}^{2} s_{2}+4 s_{1} s_{2}^{2}-s_{2}^{3}\right) \bar{\theta}^{2}}{\left(4 s_{1}-s_{2}\right)^{3}} \\
& s_{2}=\frac{s_{1}^{2}\left(4 s_{1}+s_{2}\right) \bar{\theta}^{2}}{\left(4 s_{1}-s_{2}\right)^{3}}
\end{aligned}
$$

and can be seen in Fig. 2.

From the first order conditions 7 and 8 we first numerically compute the equilibrium qualities. The quantities and profits are then obtained under NI (for details see Motta 1993). The results are shown in Table 1.

Table 1 No integration

\begin{tabular}{ll}
\hline$s_{1}^{N I}=0.251942 \bar{\theta}^{2}$ & $s_{2}^{N I}=0.090223 \bar{\theta}^{2}$ \\
$q_{1}^{N I}=0.450834 \bar{\theta}$ & $q_{2}^{N I}=0.274583 \bar{\theta}$ \\
$\pi_{U_{1}}^{N I}=0$ & $\pi_{U_{2}}^{N I}=0$ \\
$\pi_{D_{1}}^{N I}=0.019470 \bar{\theta}^{4}$ & $\pi_{D_{2}}^{N I}=0.002732 \bar{\theta}^{4}$ \\
\hline
\end{tabular}




\section{Partial Integration $\left(\mathbf{P I}_{i}\right)$}

Under Partial Integration, only one downstream firm $\left(D_{i}\right)$ integrates with the upstream firm $\left(U_{i}\right)$. This results in a single integrated firm $\left(F_{i}\right)$. Using subgame perfection we first solve for the output competition stage. The output reaction functions and the equilibrium output are the same as in the NI game (see Eqs. 1 and 2). Note that the only difference between the two is that the input price is now a transfer price for the integrated firm. We thus set $c_{i}=0$. The unintegrated firm, meanwhile, faces the input price that is determined in the third stage.

The equilibrium price equals marginal cost in the input competition stage if $F_{i}$ decides to sell the input to the downstream firm $D_{j}$. In this case, integration does not grant any advantage to $F_{i}$. In fact, $D_{i}$ loses with respect to the NI case as it incurs a cost when integrating with $U_{i}$. However, $F_{i}$ can raise its rival's cost by not selling it the input. The rival then faces a monopolist in the input market paying a monopoly price for the input. The upstream firm $U_{j}$ sets the input price maximizing profits, $\max _{c_{j}} \pi_{U_{j}}=c_{j} \cdot q_{j}\left(c_{j}, s_{i}, s_{j}\right)$ where $q_{j}\left(c_{j}, s_{i}, s_{j}\right)$ is obtained from Eqs. 3 and 4 with $c_{i}=0$.

We analyze two different cases, depending upon whether the integrated firm produces the high $\left(P I_{1}\right)$, or low $\left(P I_{2}\right)$ quality.

\subsection{Integrated firm produces high quality}

If both firms, $D_{1}$ and $U_{1}$, integrate and produce the high quality good, then firm $U_{2}$ 's profits selling the input to $D_{2}$ at price $m$ are

$$
\pi_{U_{2}}=m q_{2}\left(s_{1}, s_{2}, 0, m\right)=\frac{m s_{1}\left(s_{2} \bar{\theta}-2 m\right)}{s_{2}\left(4 s_{1}-s_{2}\right)}
$$

It is easy to see that these profits are maximized for an input price $m^{*}=$ $c_{2}^{P I}=\frac{s_{2} \bar{\theta}}{4}$. However, if firms $D_{2}$ and $U_{2}$ integrate and produce the low quality product, then the unintegrated firm $U_{1}$ can sell its input to $D_{1}$ at price $m$. Again it is easy to see that its profits, $\pi_{U_{1}}=m q_{1}\left(s_{1}, s_{2}, m, 0\right)$, are maximized setting a price, $m^{*}=c_{1}^{P I}=\frac{\left(2 s_{1}-s_{2}\right) \bar{\theta}}{4}$. One can see that the input price paid by the unintegrated firm depends on whether it produces the high, or low, quality good. It is easy to see that the price paid by the high quality firm (if the low one is integrated), $c_{1}^{P I}$, is greater than the price paid by the low quality firm (if the high one is integrated), $c_{2}^{P I}$ for the same qualities. This result is interesting as it tells us that, compared with the low quality firm, a high quality firm pays a higher price for its input. The upstream firm earns greater profits from being a monopsonist to the high quality producer than selling to a low quality producer. Note that this possibility does not arise in homogenous good models.

In the second stage of the game, firms $F_{i}$ and $D_{j}$ set qualities maximizing their profits (taking into account that firm $D_{j}$ pays a price $c_{j}^{P I}$ for each unit of the input it buys). First, consider the case $P I_{1}$, where firm $D_{1}$ and $U_{1}$ are 
integrated in $F_{1}$ and produce the high quality good. Furthermore, $D_{2}$ remains unintegrated and produces low quality. In this case, firm $F_{1}$ will face an internal price of the input, while $D_{2}$ would have to pay $c_{2}^{P I}$. Substituting these input prices, $\left(0, c_{2}^{P I}\right)$, in Eqs. 5 and 6 , firms profits are

$$
\begin{aligned}
& \pi_{F_{1}}=\frac{s_{1}\left(8 s_{1}-3 s_{2}\right)^{2} \bar{\theta}^{2}}{16\left(4 s_{1}-s_{2}\right)^{2}}-\frac{s_{1}^{2}}{2} \\
& \pi_{D_{2}}=\frac{s_{1}^{2} s_{2} \bar{\theta}^{2}}{4\left(4 s_{1}-s_{2}\right)^{2}}-\frac{s_{2}^{2}}{2}
\end{aligned}
$$

The qualities that maximize these profits are obtained from the first order conditions

$$
\begin{aligned}
\frac{\partial \pi_{F_{1}}}{\partial s_{1}} & =\frac{\left(256 s_{1}^{3}-192 s_{1}^{2} s_{2}+60 s_{1} s_{2}^{2}-9 s_{2}^{3}\right)^{2} \bar{\theta}^{2}}{16\left(4 s_{1}-s_{2}\right)^{3}}-s_{1}=0 \\
\frac{\partial \pi_{D_{2}}}{\partial s_{2}} & =\frac{s_{1}^{2}\left(4 s_{1}+s_{2}\right) \bar{\theta}^{2}}{4\left(4 s_{1}-s_{2}\right)^{3}}-s_{2}=0
\end{aligned}
$$

These implicit reaction functions are plotted in Fig. 3.

Notice that (see Fig. 3a) the reaction function of the integrated firm $F_{1}$ moves outwards and that of the unintegrated firm $D_{2}$ moves towards the

Fig. 3 Quality reaction functions $\left(R_{i}^{P I_{K}}\right.$ for firm $i=1,2$ ) when only one of the firms integrates, i. e., Partial Equilibrium: a $P I_{1} \equiv$ High quality firm integrates; b $\mathrm{PI}_{2} \equiv$ Low quality firm integrates. $N I$ is the Nash Equilibrium under $\mathrm{No}$ Integration
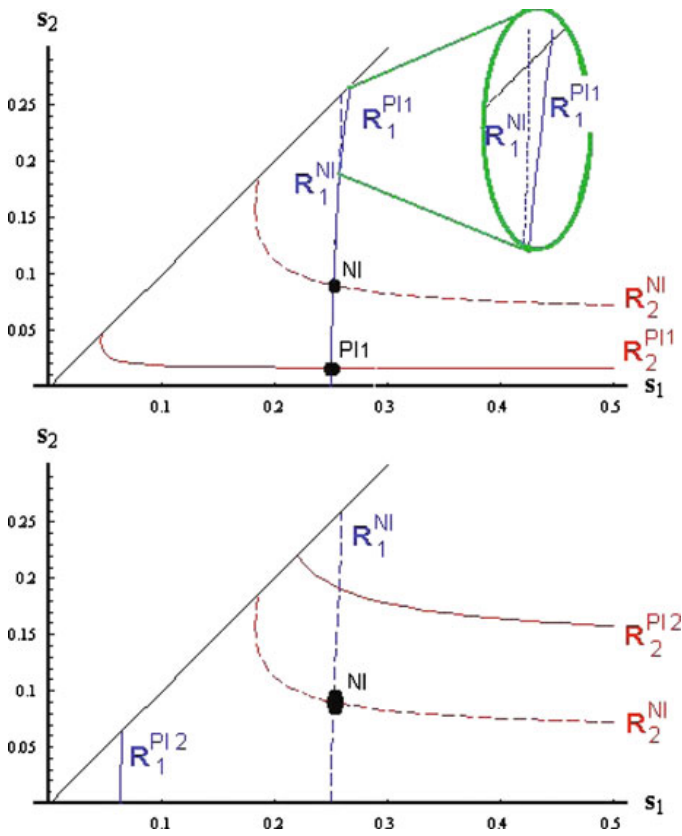
origin. An integrated firm increases production costs for the unintegrated firm (as defined by Salop and Scheffman 1983, 1987 and also obtained in OSS). The increased input price $D_{2}$ faces $\left(c_{2}^{P I}\right)$ shifts its reaction function towards the origin. The reaction function of firm $D_{1}$, however, shifts outwards due to decreased competition in the final good market (see Fig. 3b). Equilibrium qualities under $P I_{1}$, determined by the intersection of the reaction functions, are given by:

$$
s_{1}^{P I_{1}}=0.250054 \bar{\theta}^{2} s_{2}^{P I_{1}}=0.016710 \bar{\theta}^{2}
$$

Equilibrium output and profits are shown in Table 2:

\subsection{Integrated firm produces low quality}

An equilibrium in pure strategies does not exist for the case when the integrated firm produces low quality $\left(\mathrm{PI}_{2}\right)$.

Let's suppose, for example, that $D_{1}$ does not integrate and produces high quality. $D_{2}$ and $U_{2}$, meanwhile, integrate and produce low quality. Now, firm $F_{2}$ will face an internal price of the input, while $D_{1}$ would have to pay $c_{1}^{P I}$. Substituting these input prices in Eqs. 5 and 6 we obtain firm profits for firms $F_{1}$ and $D_{2}$ as

$$
\begin{aligned}
\pi_{D_{1}} & =\frac{s_{1}\left(2 s_{1}-s_{2}\right)^{2} \bar{\theta}^{2}}{4\left(4 s_{1}-s_{2}\right)^{2}}-\frac{s_{1}^{2}}{2} \\
\pi_{F_{2}} & =\frac{s_{2}\left(6 s_{1}-s_{2}\right)^{2} \bar{\theta}^{2}}{16\left(4 s_{1}-s_{2}\right)^{2}}-\frac{s_{2}^{2}}{2}
\end{aligned}
$$

The qualities that maximize these profits are obtained from the first order conditions

$$
\begin{aligned}
& \frac{\partial \pi_{1}}{\partial s_{1}}=\frac{\left(16 s_{1}^{3}-12 s_{1}^{2} s_{2}+4 s_{1} s_{2}^{2}-s_{2}^{3}\right) \bar{\theta}^{2}}{4\left(4 s_{1}-s_{2}\right)^{3}}-s_{1}=0 \\
& \frac{\partial \pi_{2}}{\partial s_{2}}=\frac{\left(144 s_{1}^{3}-60 s_{1}^{2} s_{2}+12 s_{1} s_{2}^{2}-s_{2}^{3}\right) \bar{\theta}^{2}}{16\left(4 s_{1}-s_{2}\right)^{3}}-s_{2}=0
\end{aligned}
$$

There is no real solution for these equations for $s_{1}>s_{2}$. From Fig. $3 \mathrm{~b}$ one can see that the reaction functions do not intersect in the relevant range, i.e. $s_{1}>s_{2}$. The reaction function of the low quality firm $\left(F_{2}\right)$ moves outwards due

Table 2 Partial integration: only high quality firm integrates

\begin{tabular}{ll}
\hline$q_{1}^{P I_{H}}=0.495753 \bar{\theta}$ & $q_{2}^{P I_{H}}=0.127124 \bar{\theta}$ \\
$\pi_{U_{1}}^{P I_{H}}=b_{1}$ & $\pi_{U_{2}}^{P I_{H}}=0.000531 \bar{\theta}^{4}$ \\
$\pi_{D_{1}}^{P I_{H}}=0.030192 \bar{\theta}^{4}-b_{1}$ & $\pi_{D_{2}}^{P I_{H}}=0.000130 \bar{\theta}^{4}$ \\
\hline
\end{tabular}


to the cost advantage against the rival, while the reaction function of the high quality firm $\left(D_{1}\right)$ moves inwards. The shift is large enough so that the functions do not intersect. The only case where an equilibrium in pure strategies exists is where the high quality firm integrates first. The result is summarized in the following proposition.

Proposition 1 Under Partial Integration, only an equilibrium in pure strategies exists, where the integrated firm produces the high-quality good. The costs of the unintegrated downstream firm are higher, quality differentiation is greater, and there is less market coverage than under No Integration.

\section{Full Sequential Integration $\left(\mathbf{F I}_{i}\right)$}

Now suppose that firms sequentially integrate to form two single integrated firms, $F_{i}\left(=D_{i}+U_{i}\right), i=1,2$. The first pair of firms integrates in the first stage, while the other two counter-integrate (in OSS nomenclature) in the third stage. In our model, counter-integration occurs after firms have set their quality investment. In the last stage, firms produce output maximizing profits (Eqs. 3 and 4).

The input can be considered as an internal transfer, as the firms are integrated. This implies that firms do not compete in the input market. We assume that the input prices are $c_{1}=c_{2}=0$.

In the third stage, the unintegrated firm $D_{j}$ makes an offer, $b_{j}$, to firm $U_{j}$ to integrate. The smallest amount that $U_{j}$ is willing to accept is the profit it would obtain if it were not to integrate, i.e. $b_{j}=\max _{m_{j}} \pi_{U_{j}}$, where $\pi_{U_{j}}=m_{j}$. $q_{j}\left(s_{j}, s_{i}, m_{j}, 0\right)$ and $m_{j}$ is the (monopoly) price of the input set by $U_{j}$. This input price, $m_{j}$, is identical to that obtained in the Partial Integration case.

In stage two, the "downstream" firms choose qualities that maximize their profits. There is an integrated and an unintegrated firm in this stage. Firm $D_{i}$, integrating in stage one, has already formed $F_{i}$ (paying $b_{i}$ ). As mentioned above, the unintegrated firm, $D_{j}$, meanwhile, will have to make an offer to counter-integrate with $U_{j}$ in the following stage. The counter-integration offer, $b_{j}$, is determined by the quality investment chosen in the second stage. We analyze two different cases, depending upon whether the firm that integrates first produces the high $\left(F I_{1}\right)$, or low $\left(F I_{2}\right)$, quality.

\subsection{High quality firm integrates first}

First, let's consider the case where firms $D_{1}$ and $U_{1}$ integrate in the first stage, forming $F_{1}$, and produce high quality. Then, the demand of $\mathrm{U}_{2}$ is equal to the quantity produced by $D_{2}$. If $U_{2}$ does not accept to integrate in the counterintegration stage, its maximum profits are:

$$
\pi_{U_{2}}=c_{2}^{P I} q_{2}\left(s_{1}, s_{2}, 0, c_{2}^{P I}\right)=\frac{s_{1} s_{2} \bar{\theta}^{2}}{8\left(4 s_{1}-s 2\right)}
$$


Therefore, the offer that $D_{2}$ makes to $U_{2}$ will be, $b_{2}\left(s_{1}, s_{2}\right)=\frac{s_{1} s_{2} \bar{\theta}^{2}}{8\left(4 s_{1}-s 2\right)}$. Profits of the integrated firm $F_{1}$ are then

$$
\pi_{F_{1}}=\frac{s_{1}\left(2 s_{1}-s_{2}\right)^{2} \bar{\theta}^{2}}{\left(4 s_{1}-s 2\right)^{2}}-\frac{s_{1}^{2}}{2}
$$

while $D_{2}$ 's profits (integrating) will then be

$$
\pi_{D_{2}}=\frac{s_{1}^{2} s_{2} \bar{\theta}^{2}}{\left(4 s_{1}-s 2\right)^{2}}-\frac{s_{2}^{2}}{2}-b_{2}\left(s_{1}, s_{2}\right)
$$

(this is obtained substituting zero input prices for both firms in Eqs. 5 and 6). As mentioned earlier, $D_{2}$ 's optimal investment decision, $s_{2}$, is conditioned by its subsequent effect on the bid, $b_{2}$. That is, a higher $s_{2}$ implies a higher $b_{2}$ (note that $\frac{\partial b_{2}\left(s_{1}, s_{2}\right)}{\partial s_{1}}=-\frac{s_{2}^{2} \bar{\theta}^{2}}{8\left(4 s_{1}-s 2\right)^{2}}<0$ and $\frac{\partial b_{2}\left(s_{1}, s_{2}\right)}{\partial s_{2}}=\frac{s_{1}^{2} \bar{\theta}^{2}}{2\left(4 s_{1}-s 2\right)^{2}}>0$ ).

In the second stage, both integrated and unintegrated firms select their quality in order to maximize profits. First order conditions are

$$
\begin{aligned}
& \frac{\partial \pi_{1}}{\partial s_{1}}=\frac{\left(16 s_{1}^{3}-12 s_{1}^{2} s_{2}+4 s_{1} s_{2}^{2}-s_{2}^{3}\right) \bar{\theta}^{2}}{\left(4 s_{1}-s_{2}\right)^{3}}-s_{1}=0 \\
& \frac{\partial \pi_{2}}{\partial s_{2}}=\frac{s_{1}^{2}\left(4 s_{1}+3 s_{2}\right) \bar{\theta}^{2}}{2\left(4 s_{1}-s_{2}\right)^{3}}-s_{2}=0
\end{aligned}
$$

Note that the quality reaction function of firm $D_{2}$ in the second stage shifts towards the origin (see Fig. 4a). The reason behind this is that the bid $D_{2}$ makes (in the fourth stage) depends directly upon the quality it selects (in this stage). This results in decreased incentives to invest in quality.

Comparing with the case of Partial Integration we find that the firm that integrates first cannot raise its rivals costs (input costs are the same for both firms). It does, however, raise the price firm $D_{2}$ has to pay in order to vertically integrate at a later stage. Equilibrium qualities, determined by the intersection of the reaction functions, are given by:

$$
s_{1}^{F I_{1}}=0.250385 \bar{\theta}^{2} \quad s_{2}^{F I_{1}}=0.039411 \bar{\theta}^{2}
$$

and output and profits in equilibrium are shown in Table 3.

\subsection{Low quality firm integrates first}

Now, consider the case where integrating first, a firm forms $F_{2}$ and produces low quality. The offer made by firm $D_{1}$ to integrate with $U_{1}$, will then be $b_{1}\left(s_{1}, s_{2}\right)=\frac{\left(2 s_{1}-s_{2}\right)^{2} \bar{\theta}^{2}}{8\left(4 s_{1}-s\right)}$. A firms' quality choice is conditioned by the bid firm $D_{1}$ makes to counter-integrate. 
Fig. 4 Quality reaction functions $\left(R_{i}^{F I_{K}}\right.$ for firm $i=1,2$ ) when both firms integrate sequentially, i.e., Full Integration: a $F I_{1} \equiv$ High quality firm integrates first; b $F I_{2} \equiv$ Low quality firm integrates first. $N I$ is the Nash Equilibrium under No Integration
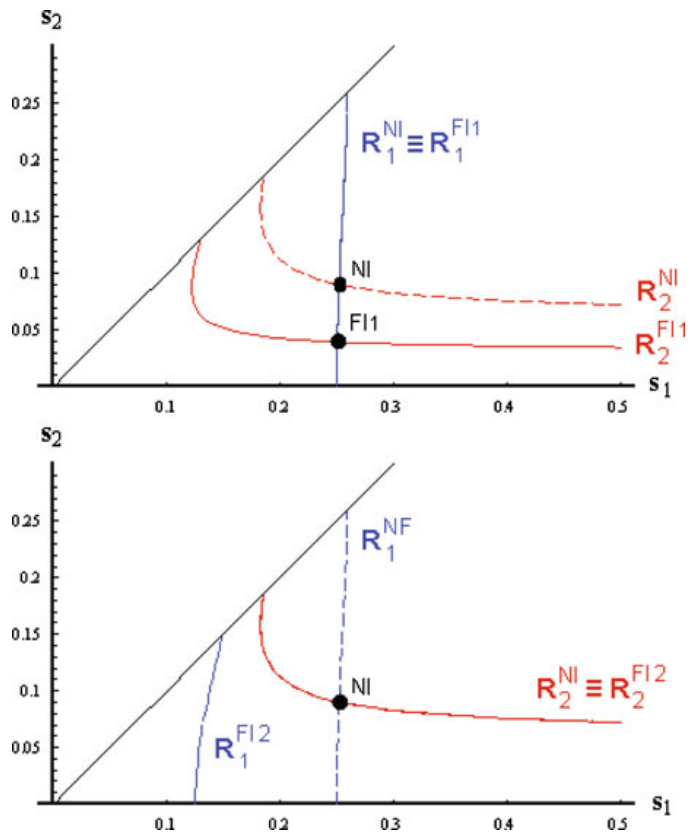

Firms select quality to maximize their profits

$$
\begin{aligned}
& \pi_{D_{1}}=\frac{s_{1}\left(2 s_{1}-s_{2}\right)^{2} \bar{\theta}^{2}}{\left(4 s_{1}-s 2\right)^{2}}-\frac{s_{1}^{2}}{2}-b_{1}\left(s_{1}, s_{2}\right) \\
& \pi_{F_{2}}=\frac{s_{1}^{2}\left(4 s_{1}+s_{2}\right) \bar{\theta}^{2}}{16\left(4 s_{1}-s_{2}\right)^{3}}-s_{2} \frac{s_{1}^{2} s_{2} \bar{\theta}^{2}}{\left(4 s_{1}-s 2\right)^{2}}-\frac{s_{2}^{2}}{2}
\end{aligned}
$$

(substituting zero input prices for both firms in Eqs. 5 and 6). The reaction function for the integrated firm $F_{2}$,

$$
\frac{\partial \pi_{F_{2}}}{\partial s_{2}}=\frac{s_{1}^{2}\left(4 s_{1}+s_{2}\right) \bar{\theta}^{2}}{\left(4 s_{1}-s_{2}\right)^{3}}-s_{2}=0
$$

Table 3 Full integration: high quality firm integrates first

\begin{tabular}{ll}
\hline$q_{1}^{F I_{H}}=0.479519 \bar{\theta}$ & $q_{2}^{F I_{H}}=0.260241 \bar{\theta}$ \\
$\pi_{U_{1}}^{F I_{H}}=b_{1}$ & $\pi_{U_{2}}^{F I_{H}}=b_{2}=0.001282 \bar{\theta}^{4}$ \\
$\pi_{D_{1}}^{F I_{H}}=0.026227 \bar{\theta}^{4}-b_{1}$ & $\pi_{D_{2}}^{F I_{H}}=0.000610 \bar{\theta}^{4}$ \\
\hline
\end{tabular}


is the same as the one for $D_{2}$ in the $N I$ case $^{22}$ (see Fig. 4b). The reaction function of the unintegrated firm, $D_{1}$,

$$
\frac{\partial \pi_{D_{1}}}{\partial s_{1}}=\frac{\left(8 s_{1}^{3}-6 s_{1}^{2} s_{2}+3 s_{1} s_{2}^{2}-s_{2}^{3}\right) \bar{\theta}^{2}}{\left(4 s_{1}-s_{2}\right)^{3}}-s_{1}=0
$$

shifts towards the origin. This shift is due to the fact that a higher quality increases the offer that it makes at a later stage (note that $\frac{\partial b_{1}\left(s_{1}, s_{2}\right)}{\partial s_{1}}=\frac{s_{1}\left(2 s_{1}-s_{2}\right) \bar{\theta}^{2}}{\left(4 s_{1}-s 2\right)^{2}}>$ 0 and $\left.\frac{\partial b_{1}\left(s_{1}, s_{2}\right)}{\partial s_{2}}=-\frac{\left(12 s_{1}^{2}-8 s_{1} s_{2}+s_{2}^{2}\right) \bar{\theta}^{2}}{8\left(4 s_{1}-s 2\right)^{2}}<0\right)$. Obviously, a higher offer decreases its profits. As a result, the reaction functions of the two firms do not cross. Once more, an equilibrium in pure strategies does not exist for the case where the low quality firm integrates first (case $F I_{2}$ ). The only equilibrium in pure strategies is one where the firm integrating first, produces the high quality good. The counter-integrating firm, meanwhile, produces low quality. A firm with the first mover advantage thus produces high quality.

Proposition 2 When both firms integrate sequentially, in equilibrium, the firm that integrates first (later) produces the high (low) quality good. Downstream firms do not face an increase in their production costs, but quality differentiation increases (with respect to the No Integration case). Market coverage is higher than under No Integration.

\section{Equilibrium market structure}

We now discuss the equilibrium of the entire game. We know that, if a firm integrates in the first period, then the unintegrated downstream firm counterintegrates later. This is due to the fact that its profits, under $F I_{1}$, are higher than under $P I_{1}$. Solving the first stage of the game, i.e. the bidding stage, we obtain the final market structure.

We assume the same simple bidding mechanism as in OSS. Both downstream firms bid for only one upstream firm with 'take it or leave it' offers. The maximum amount that each firm is willing to pay is the difference between its profits from winning, or losing, the bid. The firm winning the bid earns, $\pi_{D_{1}}^{F I_{1}}=$ $0.026227 \bar{\theta}^{4}$. A firm submitting a losing bid, will counter-integrate later and earn $\pi_{D_{2}}^{F I_{1}}=0.000610 \bar{\theta}^{4}$. By symmetry, both downstream firms are willing to pay the difference between these two profits, i.e. $b_{1}=\pi_{D_{1}}^{F I_{1}}-\pi_{D_{2}}^{F I_{1}}=0.025617 \bar{\theta}^{4}$. Given the structure of the remainder of the game, the upstream firm earns zero if it does not accept the offer, therefore, it accepts $b_{1}$.

\footnotetext{
${ }^{22}$ Using the same reasoning as in the $F I_{1}$ case.
} 
Then, the only unique equilibrium of the game is with both downstream firms bidding $b_{1}$ to integrate with an upstream firm. The winning downstream firm produces the high quality product. The other firm, meanwhile, produces low quality and counter-integrates later. Downstream firms face a prisoner's dilemma scenario. Both firms would be better off if there were no possibility to integrate.

One of the important results we obtain is that in the same structure as OSS, and without the possibility of setting a reserve price, downstream firms find it profitable to integrate. By doing so they increase rival costs. This increase is not related with an increase in production costs, but in the counterintegration bid. For the firm that integrates first, the decision to vertically integrate implies a fixed cost in terms of quality and output. For the firm that integrates later it is different. Its quality investment directly influences the offer it makes to vertically integrate. The low quality firm decreases its quality investment so as not to punish itself later. Due to this, quality investment for both firms decreases, with the decrease for the low quality firm being of a greater magnitude. ${ }^{23}$ The degree of product differentiation increases as the quality ratio drecreases, from $\frac{s_{2}}{s_{1}}=0.36$ (under $N I$ ) to $\frac{s_{2}}{s_{1}}=0.16$ (under $F I_{1}$ ). Given that its rival endogenizes integration costs, and subsequently decreases competition in qualities, vertical integration permits the firm that integrates first to attain profits close to the monopoly level. ${ }^{24}$

Our results differ from OSS if one does not consider the reserve price assumption they make. They obtain total integration, with no change in the equilibrium values for price and output. Note that a redistribution of profits does take place in their case, with the profits for the downstream firms decreasing by the same amount as the profits for the upstream firms increase.

The main feature of our model is that investment in quality is a long run variable. Integrating first, a firm is able to increase its profits and the costs of its unintegrated rival. Both the production and quality costs for the unintegrated rival, meanwhile, increase. The effect of the increase in quality investment in our model is similar to reserve price that OSS use (exogenously) to obtain foreclosure.

\section{Welfare analysis}

Total consumer surplus, $C S$, can be written as:

$$
C S=C S_{1}+C S_{2}
$$

\footnotetext{
${ }^{23}$ Note that the subsequent offer is also decreasing in the high quality level.

${ }^{24} \mathrm{High}$ quality firm takes advantage of the lessening competiton: low quality falls from $s_{2}^{N I}=$ $0.090223 \bar{\theta}^{2}$ to $s_{2}^{F I_{H}}=0.039411 \bar{\theta}^{2}$.
} 
Table 4 Profits, consumer surplus and total welfare

\begin{tabular}{llll}
\hline & $N I$ & $P I_{H}$ & $F I_{H}$ \\
\hline$q_{1}+q_{2}$ & $0.72542 \bar{\theta}$ & $0.62288 \bar{\theta}$ & $0.73976 \bar{\theta}$ \\
$\sum_{i=1}^{2}\left(\Pi_{D_{i}}+\Pi_{U_{i}}\right)$ & $0.02220 \bar{\theta}^{4}$ & $0.03085 \bar{\theta}^{4}$ & $0.02812 \bar{\theta}^{4}$ \\
$C S_{1}$ & $0.03677 \bar{\theta}^{4}$ & $0.03178 \bar{\theta}^{4}$ & $0.03370 \bar{\theta}^{4}$ \\
$C S_{2}$ & $0.00340 \bar{\theta}^{4}$ & $0.00014 \bar{\theta}^{4}$ & $0.00133 \bar{\theta}^{4}$ \\
$C S$ & $0.04017 \bar{\theta}^{4}$ & $0.03192 \bar{\theta}^{4}$ & $0.03504 \bar{\theta}^{4}$ \\
$T W$ & $0.06238 \bar{\theta}^{4}$ & $0.06277 \bar{\theta}^{4}$ & $0.06316 \bar{\theta}^{4}$ \\
\hline
\end{tabular}

where $C S_{1}\left(=\int_{\hat{\theta}_{H L}}^{\bar{\theta}}\left(\theta s_{1}-p_{1}\right) d \theta\right)$ and $C S_{2}\left(=\int_{\hat{\theta}_{0 L}}^{\hat{\theta}_{H L}}\left(\theta s_{2}-p_{2}\right) d \theta\right)$ are the consumer surplus for the high, and low quality consumers, respectively. Substituting Eqs. 3 and 4 in Eq. 9 we obtain

$$
\begin{aligned}
C S\left(c_{1}, c_{2}, s_{1}, s_{2}\right)= & \frac{\left(\left(2 s_{1}-s_{2}\right) \bar{\theta}-2 c_{1}+c_{2}\right)\left[s_{1}\left(2 s_{1}+s_{2}\right) \bar{\theta}-3 s_{1} c_{2}-2 c_{1}\left(s_{1}-s_{2}\right)\right]}{2\left(4 s_{1}-s_{2}\right)^{2}} \\
& +\frac{\left(s_{1} s_{2} \bar{\theta}-2 c_{2} s_{1}+s_{2} c_{1}\right)^{2}}{2 s_{2}\left(4 s_{1}-s_{2}\right)^{2}}
\end{aligned}
$$

We define total welfare, $T W$, as the sum of firm profits and consumer surplus. Table 4 shows the total welfare for the cases previously analyzed. Firms would gain globally if only the high quality firm were to integrate. Total profits increase when firms integrate sequentially. This is due to the softening of competition, in this case.

For consumers, it is best if firms do not integrate, or integrate simultaneously. ${ }^{25}$ Under $F I_{1}$, where vertical integration influences long run variables, total consumer surplus decreases overall. The negative effect on the consumers demanding the low quality good is greater. Although, market coverage increases under $F I_{1}$, with respect to $N I$.

OSS show that the possibility to integrate does not affect the society globally. In their case, total welfare is the same under $N I$ and $F I .{ }^{26}$ However, in our model, if firms integrate sequentially $\left(F I_{1}\right)$ then Total Welfare is greater than under No Integration $(N I)$. This increase is due to the increase in profits for input producing and the high quality firm that integrates first.

Proposition 3 In equilibrium, the market structure is Full Integration. Total welfare is higher than under No Integration. Although consumer surplus and downstream profits decrease, upstream firm profits increase substantially.

\footnotetext{
${ }^{25}$ Note that under simultaneous integration, only profit redistribution takes place with total welfare remaining unchanged.

${ }^{26}$ This result is obtained in our model only if the firms integrate simultaneously. OSS only consider sequential integration. Allowing for simultaneous integration in their model, one obtains a totally integrated industry (as in our case).
} 


\section{Conclusion}

We study the incentives to vertically integrate in vertically differentiated industries. Taking into account endogenous quality investment, we observe that vertical integration by a firm does not simply increase production costs for the rival. Vertical integration also changes the incentives to invest in quality for both the firms. The high quality firm integrating first increases the costs for the unintegrated downstream rival. This increase is not directly an increase in quality costs, but instead, increased quality investment is reflected in the increased offer it has to make to counter-integrate later. Increasing rival production costs, an integrated firm is able to decrease quality investment for both firms. Our paper points out the importance of taking into account investment in long run variables in such industries. Considering the research on regulated industries, ours is the first paper to point out the negative effect on quality investment due to vertical integration.

Interestingly, some of our results are along the lines suggested in the OECD report meantioned earlier. We find that in equilibrium, both firms decrease quality investment, thus increasing product differentiation. The decrease in quality increases the price to quality ratio. This is the reason why consumer welfare declines. We find that profits of both upstream firms increase substantially. We do not find that total welfare decreases due to Full Integration. In our case, total welfare increases due to the increase in total profits. Consumer surplus, on the other hand, does not decline substantially as the quantity sold decreases. The net effect is an increase in total welfare. The increase in total welfare comes from increased profits in our analysis.

Analyzing sequential mergers, we find that the market structure that maximizes social welfare is Full Integration. While upstream firms earn higher profits, downstream firms earn less profits. Consumer surplus decreases as a consequence of higher prices and lower quality investments. Total welfare, in this case, is greater than under No Integration.

The main difference between our paper and OSS is that they limit their analysis to short run variables, such as output and price. In their model, a firm paying a price greater than marginal cost is able to offset this by vertically integrating. Both, then, face the same conditions in the output competition stage. This is, however, not the case in our model, where quality investment is sunk when the firm integrates in the following period. As a result, counterintegration does not restore the initial conditions. The firm that integrates later obtains lower profits. This is due to the fact that an increase in quality implies a higher offer that a firm has to pay (later on) to integrate. As a result, firm investment in quality decreases relative to No Integration. The high quality firm takes advantage of this situation, investing less in quality and increasing its profits. ${ }^{27}$

\footnotetext{
${ }^{27}$ Profits before making the integration bid.
} 
The result obtained in OSS is a partially integrated industry, where the integrated firm sells the input to its rival at a "reserve price", such that the rival's profits with, or without, integration are the same. This aspect of their model has been criticized in the literature, as it is not an equilibrium of the game they study. ${ }^{28}$ Without the possibility of the reserve price, the result in their model resembles a prisoners' dilemma, where the industry is totally integrated. Price and output obtained are the same as under No Integration. Downstream firms transfer part of their profits to the upstream firms as a payment for integrating. In our model, however, there is no need to establish such a reserve price. Full Integration is observed with one important difference: total welfare increases as qualities, prices and outputs change with respect to No Integration.

Even though quality investment declines and product differentiation increases, from the social viewpoint, sequential vertical integration is beneficial. The firm that integrates first is the one that benefits the most by increasing the integrating costs of its rival. This result is obtained in spite of the fact that in our model, vertical integration does not entail elimination of double marginalization.

Acknowledgements Hernan and Kujal acknowledge support from grant 2009/00055/001 from the Spanish Ministry of Education. Kujal acknowledges support from the Instituto Universitario de Economía, Consolider-Ingenio 2010 and the Comunidad de Madrid (grant Excelecon).

\section{References}

Aghion P, Bolton P (1987) Contracts as a barrier to entry. Am Econ Rev 77:338-401

Avenel E, Barlet C (2000) Vertical foreclosure, technological choice, and entry on the intermediate market. J Econ Manage Strategy 9:211-230

Banerjee S, Lin P (2003) Downstream R\&D, raising rivals costs and input price contracts. Int J Ind Organ 21:79-96

Brocas I (2003) Vertical integration and incentives to innovate. Int J Ind Organ 21:457-488

Chen Y (2001) On vertical mergers and their competitive effects. RAND J Econ 32:667-685

Chen Y, Riordan M (2007) Vertical integration, exclusive dealing, and ex post cartelization. RAND J Econ 38:1-21

Choi JP, Yi S (2000) Vertical foreclosure with the choice of input specifications. RAND J Econ 31:717-743

Cooper J, Froeb L, O'Brien D, Vita M (2005) Vertical antitrust policy as a problem of inference. Int J Ind Organ 23:639-664

Economides N (1998) The incentive for non-price discrimination by an input monopolist. Int J Ind Organ 16:271-284

Foros O (2004) Strategic investments with spillovers, vertical integration and foreclosure in the broadband access market. Int J Ind Organ 22:1-24

Hart O, Tirole J (1990) Vertical integration and market foreclosure. Brookings Pap Econ Act Microecon 1990:205-276

Lafontaine F, Slade M (2007) Vertical integration and firm boundaries: the evidence. J Econ Lit 45:629-685

\footnotetext{
${ }^{28}$ See Hart and Tirole (1990), Ordover et al. (1992), Reiffen (1992) and Avenel and Barlet (2000)
} for a detailed discussion. 
Martin S, Normann H, Snyder C (2001) Vertical foreclosure in experimental markets. RAND J Econ 32:466-496

Motta M (1993) Endogenous quality choice: price vs. quantity competition. J Ind Econ 2:113-132

OECD (2007) Policy roundtable on vertical mergers. http://www.oecd.org/dataoecd/25/49/39891031. pdf

Ordover JA, Saloner G, Salop SC (1990) Equilibrium vertical foreclosure. Am Econ Rev $80: 127-142$

Ordover J, Salonerm G, Salop S (1992) Equilibrium vertical foreclosure: reply. Am Econ Rev 82:698-703

Rasmusen E, Ramseyer J, Wiley J (1991) Naked exclusion. Am Econ Rev 81:1137-1145

Reiffen D (1992) Equilibrium vertical foreclosure: comment. Am Econ Rev 82:694-697

Salinger M (1988) Vertical mergers and market foreclosure. Q J Econ 103:345-356

Salop S, Scheffman D (1983) Recent advances in the theory of industrial structure. raising rivals' costs. Am Econ Rev: Pap Proc 73:267-271

Salop S, Scheffman D (1987) Cost-raising strategies. J Ind Econ 36:19-34

Shaked A, Sutton J (1983) Natural oligopolies. Econometrica 51:1469-1483

Sibley D, Weisman D (1998) Raising rivals' costs: the entry of an upstream monopolist into downstream markets. Inf Econ Policy 10:451-470

Stefanadis C (1997) Downstream vertical foreclosure and upstream innovation. J Ind Econ 45:445456

Vickers J (1995) Competition and regulation in vertically related markets. Rev Econ Stud 62:1-17 